\title{
The Determinants of the Reproductive Health of Women of Tai-Aiton Community of Assam
}

\author{
Pollypriya Buragohain
}

\begin{abstract}
Reproductive Health is one of the significant issues today as it is a pivotal part of general health. Reproductive health was defined in International Conference on Population and Development (ICPD) as "the state of complete physical, mental and social well-being and not merely the absence of disease or infirmity, in all matters relating to the reproductive system and to its functions and processes"(ICPD Programme of Action, paragraph 7.2). Worldwide maternal deaths fell by almost 44 percent from 1990 to 2015, but about 830 mothers still die daily in delivery cases or as a result of pregnancy or post partum causes. The health status of tribal women is very poor (Ramana, 2015). The Tai-Aitons are a recognizable scheduled tribe of Assam having their own distinctive culture and tradition. They have been recognized as Scheduled Tribes (Hills) and are listed as Man-Tai Speaking people by the Government of Assam. No specific data about the total population of the Tai-Aitons are available. Though data are not accessible, but various studies exhibit that population of Tai-Aitons is very less. There are number of factors which may influence the reproductive health of the above mentioned women of Tai-aiton community. So, the basic objective of this study is to find out and analyze the main determinants of the reproductive health of women of Tai-Aiton community of Assam. Data is collected from two development blocks of Karbi-Anglong district and one development block of Golaghat district (total 210 households) based on the data of Man-Tai Speaking National Council, Assam, Population Cum Education Census (2006). The data related to this study are collected from August 2019 to October 2019. In order to examine the influence of socio-economic and demographic factors on the reproductive health of the sample women, Multiple Linear Regression analysis has been carried out where value of Reproductive Health Index is taken as dependent variable. The result of the study find out that live birth ever born, education of women, distance to PHCs, occupation of husbands, age at birth of the females and infant mortality affect significantly and occupation of women, monthly income, exposure to mass media and birth interval does not significantly affect the reproductive health of the Tai-Aiton women of Assam. Thus, ensuring a better reproductive health of the women, it is mandatory to improve education among girls particularly beyond high school in tribal areas because education impacts upon the health status particularly the reproductive health status of women. In tribal areas, the Integrated Maternal and Child Health programme may also play an important role in improving the education level mostly take an important step to make aware of the tribal women about their health particularly their nutrition level.
\end{abstract}

Key Words: Reproductive Health, Tai-Aiton, Maternal, Women,Assam.
Revised Manuscript Received on April 30, 2020.

* Correspondence Author

Pollypriya Buragohain*, M.Phil research scholar Department of economics, dibrugarh university, assam

(C) The Authors. Published by Blue Eyes Intelligence Engineering and Sciences Publication (BEIESP). This is an open access article under the CC BY-NC-ND license (http://creativecommons.org/licenses/by-nc-nd/4.0/)

\section{INTRODUCTION}

Reproductive Health characterizes the absolute health condition of a population and mainly implies the women's health, right and empowerment. Reproductive Health is a crucial part of general health and a central feature of human development. Recent statistics of World Health Organization (2013) show that maternal mortality are second largest subscriber to the universal disease burden of women at their reproductive age. Worldwide maternal deaths fell by almost 44 percent from 1990 to 2015, but about 830 mothers still die daily in delivery cases or as a result of pregnancy or post partum causes. The health status of tribal women is very poor (Ramana, 2015). The TaiAitons are a recognizable scheduled tribe of Assam having their own distinctive culture and tradition. They have been recognized as Scheduled Tribes (Hills) and are listed as Man-Tai Speaking people by the Government of Assam. No specific data about the total population of the Tai-Aitons are available. Though data are not accessible, but various studies exhibit that population of Tai-Aitons is very less. There are number of factors which may influence the reproductive health of the above mentioned women of Taiaiton community. Women's reproductive health is influenced by many factors such as live birth, education of women, occupation of husbands, distance to health care centre etc.

The present study tries to examine the different kind of socio-economic and demographic factors which may influence the reproductive health of women of the Tai-Aiton community of Assam.

\section{LITERATURE REVIEW}

This study is mainly empirical in nature.

An interesting research was done by Pandey and Tiwari (1991) on the attributes of Tribal households (1297) with non-tribal households (915) of Kundan block area of Jabalpur district, Madhya Pradesh. In their study, it was found that the tribal households varied in case of working status (higher percentage engaged in agriculture) and education level(higher percentage have low level of education).

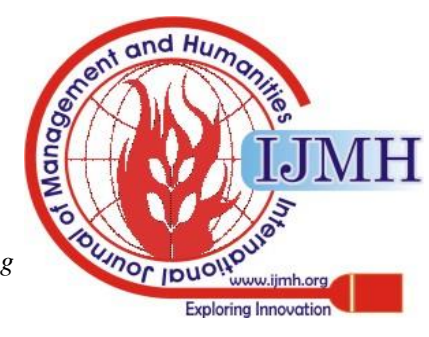




\section{The Determinants of the Reproductive Health of Women of Tai-Aiton Community of Assam}

Natonal Institute of Nutrition (NIN), 1992 had conducted a study on socio-cultural conditions of health status among the Kamar Tribe. In their study, it was found that most of the population of Kamar tribe was underpriviledged, uneducated and usually irrational. Among this tribe, age at marriage of the females was high and newly married women had price rate. They believed that nuptial age of a girl was immediately after their puberty and the mean age at puberty was 13-18 years. They only knew about the sterilization method of family planning.

Chauhan (1993) in his research work it was found that status of Tribal women of Madhya Pradesh by examining their position in the Tribal Social Institutions. He found that Sahari women were dependent on men and they were disparaged in their working structure and they strictly followed some ritual beliefs.

A study also done by Rao (2002) by analyzing the socioeconomic condition of tribal women in Arunachal Pradesh by considering the determinants such as education and economic strength. He found that a high percentage of women were engaged in allowance employment activity and in household duty in the study area. It was found that in Arunachal Pradesh average of females engage in activities over 12 hours in a day and again it was found in his study that a satisfying number of NGOs have been established in Arunachal Pradesh for improving the standard of women and strengthen the level of education.

An interesting study has made by Sundaram (2004) by examining the hurdles related to strengthen the power of Tribal women. In his study, he observes various problems among the Tribal women such as early marriage problem, lack of education, deprivation, poverty, under nutrition etc. By considering the problems of tribal population, suggestions are provided to upgrading the nourishment level of the population.

Kantidas (2012) has studied about the socioeconomic condition of tribal women in India. In his study he has analysed some restraints of strengthening the women in the Tribal areas of Assam. Kantidas has also found that status and strength of Tribal women was poor due to lack of modernize and information knowledge and also their main hurdles are intellectual and foundational for development.

In his study, Rao (2013) has found out the socioeconomic status of the scheduled tribes living in Visakhapatnam of Andhra Pradesh, India. He has found out that majority of households are belonged to Hinduism and bulk of them are uneducated so that there is a necessity to give concentration on status of education of scheduled tribes.

\section{METHODOLOGY}

To deal with the objective of the study, an appraising and explanatory method is adopted for the study. The study is based on both primary and secondary data sources.

The secondary data have been collected from various Government reports and other research organizations which deal with reproductive health.

Here, primary data are collected from the respondents by employing a well-structured interview schedule. The researcher visited each household and collected relevant data from the members. The respondents extended full cooperation in the process of data collection. The data pertain to the study 2014-2018. In this study, the primary data have

been compiled from a sample of 210 households, following a multistage sampling technique (both random and purposive) for drawing the samples.

Majority of the Tai-Aitons are found in Golaghat and Karbi-Anglong districts of Assam. Among three subdivisions of Karbi-Anglong district, viz., Diphu Sadar subdivision, Bokajan Civil sub-division and Hamren Civil subdivision, Bokajan Civil sub-division is chosen for the survey. Again among four sub-divisions, viz., Golaghat, Bokakhat, Dhansiri and Merapani; Dhansiri sub-division is selected as sample sub-division. Two blocks, i.e., Bokajan Development Block and Nilip Development Block under Bokajan Civil sub-division are choosen for the survey and Sarupathar Development Block is selected as sample block under Dhansiri sub-division.

There are total six Tai-Aiton living villages in Bokajan Development Block and Nilip Development Block of KarbiAnglong district and all these six villages are selected. In Golaghat district, there are three Tai-Aiton living villages under Sarupathar Development Block and all the three are selected for data collection. Lastly, $60 \%$ of households from each sample Tai-Aiton villages are selected as sample households for the primary survey and total 210 households are selected as sample households for the study. Table 1 shows the statistical procedure of collecting primary information.
Published By:

Blue Eyes Intelligence Engineering

\& Sciences Publicati 
Table 1: Primary data collection procedure

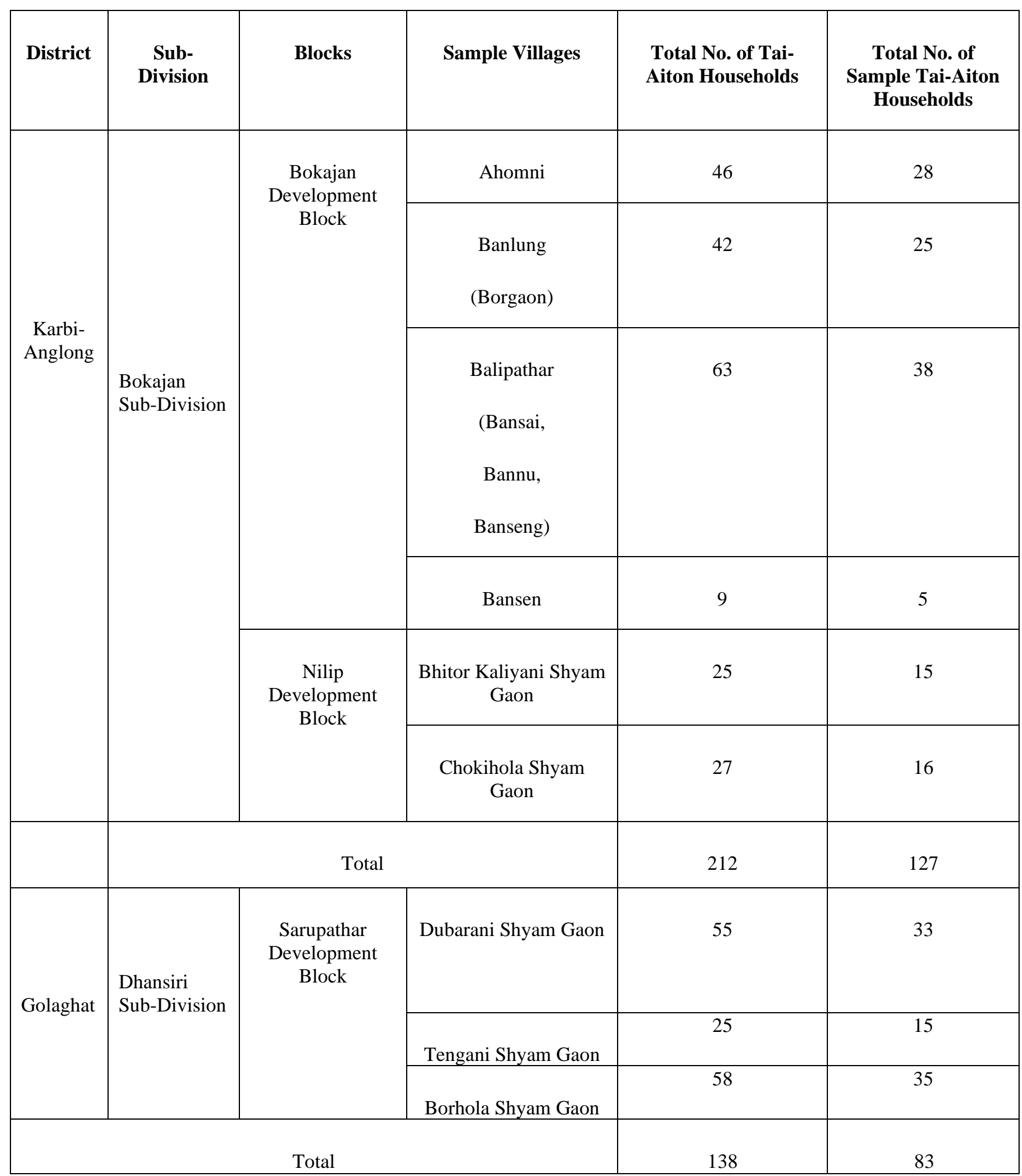

Source: Man-Tai Speaking National Council, Assam, Population Cum Education Census (2006)

The table shows that total 210 Tai-Aiton households are randomly selected for the survey. The data related to this study are collected from August 2019 to October 2019. To collect the information regarding reproductive health status, one married women belonging to age group 15-49(married only once) who experienced her last pregnancy during 20142018,i.e.,five years prior to survey has been chosen.

\section{RESULT ANALYSIS}

Conceptual overview of the explanatory variables in the present study:

Published By:

Blue Eyes Intelligence Engineering

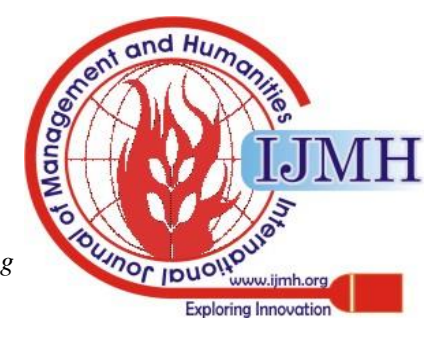


(i) Live Birth Ever Born : The term 'live birth' means that any infant who shows the evidence of live after the separation of mother's uterus. There is a long term implications for a woman's health that has experienced of giving birth. Prior studies have found that higher birth adversely affects the reproductive health of a woman but it does not mean that childlessness is good for better reproductive health.

(ii) Age at birth of the female : Higher the age at birth and reproductive health of women are also positively related. At the time of first birth, if the woman is young; it indicates a longer child bearing period as she is likely to have more children which may increase the risk to the health of both mothers and the baby. Reproductive health of a young mother and increasing the age at first birth is positively correlated. Increasing age at first birth helps to both mother and the child. This concept can also help a young mother from socio-economic and mental context and it secures their reproductive health in future (MEASURE DHS). health are correlated. The impact of education has a positive impact on reproductive health. Education also improves the women's development and maternal and child health. In case of empowerment and reach out knowledge and resources, education plays a very important role; education also helps in reduction of maternal mortality by enhancing women's knowledge on modern health care facilities.

(iv) Occupation of Husband : Husband's occupation and reproductive health of women are positively related. The nature of the work, i.e., basically agricultural work (not organized sector),they have tension and irregular life schedule so that their involvement in getting timely medical check-up and to take proper reproductive health care of their wives is insufficient whereas the husbands who are not engaged in agricultural work, their wives have a god reproductive health status.

(v) Infant Mortality Experience : Infant mortality has a negative impact on women's reproductive health. Infant mortality may occur due to deficiency of some mother's reproductive health related factors like nutrition, age at birth, birth order, antenatal care, postnatal care etc. Increasing number of infant mortality may adversely affect the reproductive health of a mother. Women who have experienced child-loss are 39 percent less likely to have high reproductive health status (Raj \& Raj, 2004).

(vi) Distance to Health Facility : In everyday life, there is a large number of mothers who suffering from complicacy during pregnancy as well as postnatal period; so to alleviate this complications and reproductive health problems, improving the health care facilities and to ensure availability of such health care facilities to an attainable distance. There is a positive impact of shortest distance to PHCs on reproductive health of a woman.

\section{Model to be enforced and rationalization}

In order to examine the influence of socio-economic and demographic factors on the reproductive health of the sample women, Multiple Linear Regression analysis have been carried out. Multiple Linear Regression analysis was used in other studies also for recognizing the significant determinants affecting reproductive health status of (iii) Education of women : Education and reproductive

women(Latha,2007). Multiple Linear Regression is done as value of Reproductive Health Index is taken as dependent variable. Here, the range of the Index value is not bounded between 0 and 1, rather it contains continuous values. Again In the Multiple Linear Regression model, the following model can be framed-

$$
\mathrm{RHI}=\alpha+\sum \beta_{\mathrm{t}} \mathrm{X}_{\mathrm{t}}+\mu_{\mathrm{t}}
$$

Where, RHI= Reproductive Health Index( which indicates the Reproductive Health Status)

(Dependent Variable)

$\alpha=$ Intercept Term

$\beta \mathrm{t}=$ Regression coefficient for each of the independent variable

$\mathrm{Xt}=$ Explanatory variables mentioned

above

$\mu_{\mathrm{t}=}$ Disturbance term which includes that variables which influence the dependent variable but not included in the model

Table 2 : Recoded variables in the Multiple Linear Regression model, the following model

\begin{tabular}{|l|l|}
\hline Variables & Re-coded value \\
\hline Education of Women & Illiterate to high School=0 \\
Occupation of Husband & $\begin{array}{l}\text { Agri.\& allied, wage earner, } \\
\text { too old/sick=0 }\end{array}$ \\
\hline service, Business, \\
Professional, Pensioner=1
\end{tabular}

\section{Result of the Multiple Liner Regression analysis}

The results of the multiple linear regression analysis have been presented in the table:

Published By:

Blue Eyes Intelligence Engineering

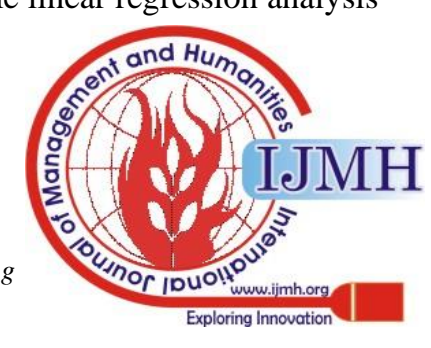


Table 3: Multiple Regression Results

\begin{tabular}{|c|c|c|c|c|c|}
\hline Regressor & $\begin{array}{c}\text { Unstandardized } \\
\text { Coefficient }\end{array}$ & $\begin{array}{c}\text { Standardized } \\
\text { Coefficient }\end{array}$ & 't'-Ratio & Tolerance & $\begin{array}{c}\text { Variance } \\
\text { Inflating Factor } \\
\text { (VIF) }\end{array}$ \\
\hline Constant & 1.275 & .468 & 2.724 & & \\
\hline LB & -.112 & .065 & $-1.735^{* * *}$ & .796 & 1.256 \\
\hline EW & .347 & .170 & $2.041^{* *}$ & .598 & 1.671 \\
\hline D & .289 & .124 & $2.322^{* *}$ & .837 & 1.195 \\
\hline OW & .255 & .231 & 1.106 & .654 & 1.529 \\
\hline OH & .239 & .124 & $1.928^{* *}$ & .814 & 1.228 \\
\hline MI & -.001 & .008 & -.096 & .809 & 1.236 \\
\hline AB & .042 & .015 & $2.848^{*}$ & .746 & 1.341 \\
\hline EMM & .043 & .117 & .370 & .978 & 1.023 \\
\hline BI & -.054 & .228 & -.237 & .919 & 1.088 \\
\hline IM & -.903 & .202 & $-4.468^{*}$ & .955 & 1.047 \\
\hline
\end{tabular}

Dependent Variable: Reproductive Health Status

$\mathrm{N}=210 ; \mathrm{R}^{2}=0.310$; Adjusted $\mathrm{R}^{2}=0.272$; Durbin

Watson=1.618; $\mathrm{F}=8.170$

$* * *=1 \%$ level of significance $(\mathrm{P}<0.01)$

$* *=5 \%$ level of significance $(\mathrm{P}<0.05)$

$*=10 \%$ level of significance $(\mathrm{P}<0.1)$

\section{Discussion of the results of multiple linear regression model:}

The Multiple Linear Regression Model depicts that the above mentioned independent variables influence the reproductive health status of the sample population. The result shows that the Reproductive Health Status of the sample women is determined by the explanatory variables to the extent of $31 \%$. It is also found that ' $F$ ' value (8.170) is significant at $1 \%$ level of confidence. The result shows that the value of Durbin Watson statisitic is 1.618 which indicates that there exists a positive autocorrelation in the regression model. In regression model, collinearity statistics satisfied the assumption of no multicollinearity among the regressors. In respect of all the predicted variables, the Variance Inflating Factor (VIF) is much below 10 ( here, it is between1.023 to 1.671). In regression model,the Tolerance(TOL) values also depict the existence of no collinearity among the regressors(here tolerance values are closer to 1 ).

\section{Analysis of the Estimated Regression Coefficients:}

The regression analysis finds live birth ever born, education of women, distance to PHCs, occupation of

Husbands, age at birth of the females and infant mortality as the significant socio-economic and demographic factors of reproductive health of sample respondents.
Regression analysis finds that live birth ever born has a negative impact with $1 \%$ level of significance on the reproductive health of respondents. The estimated regression coefficient(Live Birth) shows that the $\beta$ coefficient for live birth ever born is -.112, indicates that influence of other explanatory variables held constant, as live birth increases, say by one more child, $\mathrm{n}$ an average, reproductive health of the respondents goes down.

Education of women is also having positive 5\% level of significance on the reproductive health, which one would normally expect. The estimated regression coefficient for education of the women shows that keeping all other variables constant, reproductive health is better when women are literate.

Another significant explanatory variable which is positively related to reproductive health with 5\% level of significance is distance to nearest health facility from home (D). The estimated regression coefficient (D) shows that the $\beta$ coefficient for women having access to the health facility within $5 \mathrm{~km}$. from home is .289. This indicates that those women for whom the health facility is within $5 \mathrm{~km}$. are $71 \%$ more likely to go for institutional delivery, which have positive impact on reproductive health of the respondents than those for whom it is beyond $5 \mathrm{~km}$. Otherwise, greater distance increases the cost in terms of transportation and affordability to seek the health care facility.

Again regression analysis shows that occupation of husband has a positive impact with 5\% level of significance on the reproductive health of the respondents. The estimated regression coefficient for the occupation of husband $(\mathrm{OH})$ shows that keeping all other variables constant, when husbands are engaged in one more organized sector, it may increases the reproductive health status of the women.

Age at birth is positively related to reproductive health with $10 \%$ level of significance. Increasing the age at first birth improves the reproductive health status of women.

Published By:

Blue Eyes Intelligence Engineering DOI: 10.35940/ijmh.H0774.044820

Journal Website: www.ijmh.org

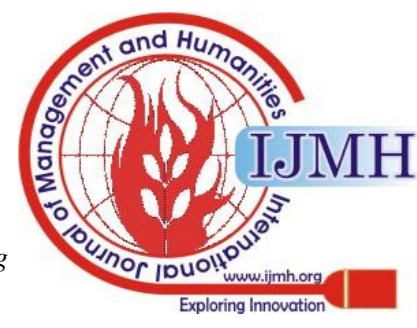




\section{The Determinants of the Reproductive Health of Women of Tai-Aiton Community of Assam}

Experience of infant mortality (IM) is found to be negatively significant with $10 \%$ level of significance on the reproductive health. The estimated regression coefficient for infant mortality experience shows that keeping all other variables constant, if the women experiencing infant mortality, reproductive health status goes down.

Other predictors included in the model such as occupation of women, monthly income, exposure to mass media and birth interval have not been found to have significant impact on the reproductive health of the sample respondents of the study.

\section{CONCLUSION}

The present paper has been concerned to find out the significant socio-economic and demographic factors that may influence the reproductive health of women of TaiAiton community of Assam. For this purpose, multiple linear regression model has been used. Thus, in conclusion it is found out that the socio-cultural factors,i.e., live birth ever born have positive $1 \%$ level of significance and education of women have positive $5 \%$ level of significance and also age at birth have $10 \%$ level of significance, likewise economic factors such as occupation of husbands have positive $5 \%$ level of significance and two demographic variables such as experience of infant mortality(10\%) and distance to nearest health facility from home(5\%) level of significance on reproductive health. In this case, experience of infant mortality has negative impact and distance to nearest health facility has a positive relation with reproductive health of women.

Thus, ensuring a better reproductive health of the women, it is mandatory to improve education among girls particularly beyond high school in tribal areas because education impacts upon the health status particularly the reproductive health status of women. It can also change the mind set, decision making power of a woman and leads a positive impact on all round development. In tribal areas, the Integrated Maternal and Child Health programme may also play an important role in improving the education level mostly take an important step to make aware of the tribal women about their health particularly their nutrition level.

\section{REFERENCES}

1. Chauhan, A. (1996). The status of Tribal women in India.Trends in Social Science Research,3(2).

2. Pandey, G.D., and Tiwari, R.S (1991): "Socio-Cultural Reproductive Health Practices of Primitive Tribes of Madhya Pradesh: Some Observations". The journal of family welfare, Socio-cultural health practices, 47(2)27-35.

3. Ramana,D.(2015): "Reproductive Health Status Issues and Concerns of Tribal Women". Ph.D. Thesis. Centre for Extension Studies \& Centre for Women's Studies. Sri Venkateswara University. Andhra Pradesh.India.

4. Rao, D. Pulla (2013). "Socio-economic Status of Scheduled Tribes". International Journal of Management. Vol 1. Issue 1. July 2013. Online at https://mpra.ub.uni-muenchen.de/48761/ MPRA Paper No. 48761, posted 31 July 2013.

5. Report of the National Institute of Nutrition(NIN),1992.

6. Sengupta, S: "Tribal Studies in North-East India". Mittal Publications. New Delhi-110059.India

7. Singh, J. \& Bora P.(2014): "Ethnic Groups of North-East India: Education, Health and Nutritional Perspective". Mittal Publications, New Delhi.India

8. Terwiel, B.J.(1970): "The Tai of Assam and Ancient Tai Ritual". Vol.I. II. Centre for South East Asian Studies Gaya.

\section{AUTHOR'S PROFILE}

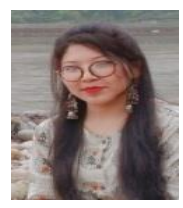

Pollypriya Buragohain, received Bachelor of Arts degree from Jagannath Baruah College, Jorhat in Economics under Dibrugarh University. She received Master of Arts in Economics from Dibrugarh University and presently she is pursuing M.Phil. Degree in Economics from Dibrugarh University, Dibrugarh, Assam , India.

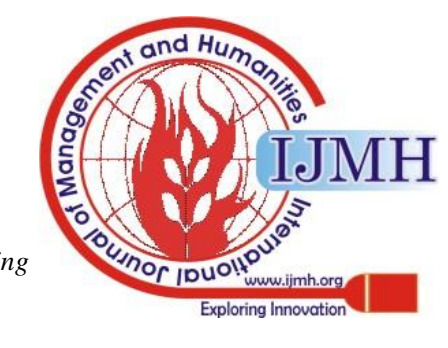

